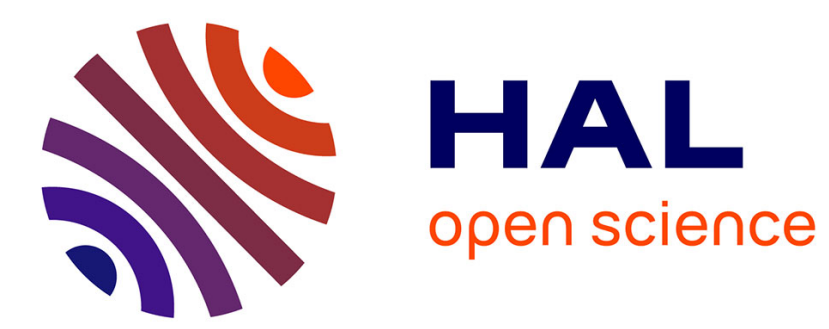

\title{
PHOTOREACTION OF CHOLESTERYL CINNAMATE
}

\author{
Y. Tanaka, H. Tsuchiya
}

\section{To cite this version:}

Y. Tanaka, H. Tsuchiya. PHOTOREACTION OF CHOLESTERYL CINNAMATE. Journal de Physique Colloques, 1979, 40 (C3), pp.C3-41-C3-44. 10.1051/jphyscol:1979310 . jpa-00218700

\section{HAL Id: jpa-00218700 https://hal.science/jpa-00218700}

Submitted on 1 Jan 1979

HAL is a multi-disciplinary open access archive for the deposit and dissemination of scientific research documents, whether they are published or not. The documents may come from teaching and research institutions in France or abroad, or from public or private research centers.
L'archive ouverte pluridisciplinaire HAL, est destinée au dépôt et à la diffusion de documents scientifiques de niveau recherche, publiés ou non, émanant des établissements d'enseignement et de recherche français ou étrangers, des laboratoires publics ou privés. 


\title{
PHOTOREACTION OF CHOLESTERYL CINNAMATE
}

\author{
Y. TANAKA and H. TSUCHIYA
}

Research Institute for Polymers \& Textiles, 4 Sawatari, Kanagawa, Yokohama 221, Japan

\begin{abstract}
Résumé. - La photoréaction du trans-cinnamate de cholestérol a été étudiée dans les phases solides, mésomorphes et isotropes dans des matrices de $\mathrm{KBr}$ de $25^{\text {à }} 225^{\circ} \mathrm{C}$ et comparée aux réactions en solution dans le $n$-hexane ou l'éther de diéthyl. Le trans-cinnamate de cholestérol est dimérisé par une irradiation à des longueurs d'onde plus grandes que $300 \mathrm{~nm}$. Dans la solution, l'irradiation du trans-cinnamate conduit à un cis-isomère à $25-30^{\circ} \mathrm{C}$. La vitesse de dimérisation dans l'état mésomorphe est plus grande qu'à l'état liquide. La réaction photochimique en phase solide est beaucoup plus lente que dans toute autre phase. La comparaison de ces résultats avec ceux obtenus en phase isotrope suggère qu'un certain type d'ordre est susceptible d'augmenter la vitesse de réaction et d'affecter son cours sans irradiation.
\end{abstract}

\begin{abstract}
The photoreaction of cholesteryl trans-cinnamate was studied in various states such as the solid, mesomorphic and isotropic liquid states in $\mathrm{KBr}$ matrix at $25-225{ }^{\circ} \mathrm{C}$, and compared with the solution reaction in $\mathbf{n}$-hexane or diethyl ether. Cholesteryl trans-cinnamate was converted into a dimer on irradiation at wave-length longer than $300 \mathrm{~nm}$ at these phases. On irradiation in the solution, this trans-cinnamate was converted into a cis-isomer at $25-30^{\circ} \mathrm{C}$. The rate of the dimerization at the mesomorphic state was found to be higher than that at the isotropic liquid state. The photoreaction in the solid phase took place at a much slower rate than in the other phases. This suggests that some kinds of ordering besides the mobility of the molecules of cholesteryl cinnamate enhance the rate and affect the course of the reaction on irradiation in comparison with the reaction in the isotropic solution.
\end{abstract}

1. Introduction. - The undercooled liquid phase and the mesomorphic state of the compound have been pointed out to be favourable for the reaction process, probably due to the fact that in the mesomorphic state the compounds are in a preoriented state while at the same time their mobility is increased relative to the solid crystalline state. Thus, the reactivity in the mesomorphic state has received an increasing amount of attention.

In the present paper, we studied the photochemical reaction of cholesteryl trans-cinnamate at various states such as the solid, liquid crystalline and isotropic liquid phases at $25-225^{\circ} \mathrm{C}$ in $\mathrm{KBr}$ matrix. Isotropic solutions of this compound in n-hexane or diethyl ether were used as reference systems. The photoreaction of some derivatives of cinnamic acids has been studied $[1,2]$ in various solvents and at the solid state, but not in the mesomorphic state. The purpose of this work is to compare the influence of the helical ordered cholesteric state and the random order of the isotropic liquid on the photoreaction.

2. Experimental. - Cholesteryl trans-cinnamate was reagent grade and recrystallized repeatedly with methyl ethyl ketone or benzene as the solvent and methanol as the precipitant. A purified sample showed a single spot in the thin layer chromatogram using a mixed solvent of cyclohexane/ethyl acetate $(99.5 / 0.5)$ or petroleum ether/diethyl ether/acetic acid $(90 / 10 / 1)$ for development at $25^{\circ} \mathrm{C}$. The phase transition temperatures of this purified sample were obtained by using capillary method, light microscopy and calorimetry. A mesomorphic phase between $163-216^{\circ} \mathrm{C}\left(162.5-215.2^{\circ} \mathrm{C}^{3}\right)$ was observed in heating curves of differential scanning calorimetry (DSC), using a Perkin Elmer differential scanning calorimeter DSC-IB. The temperature of transition was determined as peak temperature of a DSC curve.

The exciting light was furnished by an irradiator composed of a $500-\mathrm{W}$ xenon lamp as the light source and filters. The irradiation for the measurement of the quantum yields was performed with a JASCO CRM-FA spectroirradiator composed of a $2000-\mathrm{W}$ xenon lamp as the light source and a grating monochromator. The light intensity was measured by potassium ferrioxalate actinometry [4], and the actinometric estimates were checked with an Eppley thermopile.

To examine the photoreaction of cholesteryl transcinnamate, ultraviolet and infra-red absorption spectra changes of the sample were measured during reaction upon irradiation with filtered light. For this 
purpose, $\mathrm{KBr}$ pellets containing the cinnamate were prepared by pressing in an evacuated die at 13-15 kbar for $5 \mathrm{~min}$. $\mathrm{KBr}$ pellets made of carefully dried material prepared in this way were sufficiently transparent down to $220 \mathrm{~nm}$; they exibited a low degree of scattering and at low solute concentrations apparently they obeyed the Lambert-Beer law.

Ultraviolet spectra measurements were performed with a Shimadzu UV-200 spectrophotometer equipped with a holder for $\mathrm{KBr}$ pellet. To attenuate the scattered light, ultraviolet absorption spectra were measured by the method of an integrating sphere attached to a spectrophotometer. Infrared absorption spectra were obtained on a Hitachi EPI-G3 spectrophotometer equipped with $\mathrm{NaCl}$ prism.

To examine the photoreaction in solution, the cinnamate was dissolved in hexane and irradiated for $50 \mathrm{~h}$. The solvent was evaporated on a rotary evaporator and the residue was collected as the reaction mixture for analysis.

3. Results and discussion. - The ultraviolet absorption spectra of cholesteryl trans-cinnamate and representative results of photochemical experiments are shown in figure 1. On the irradiation of the cinnamate

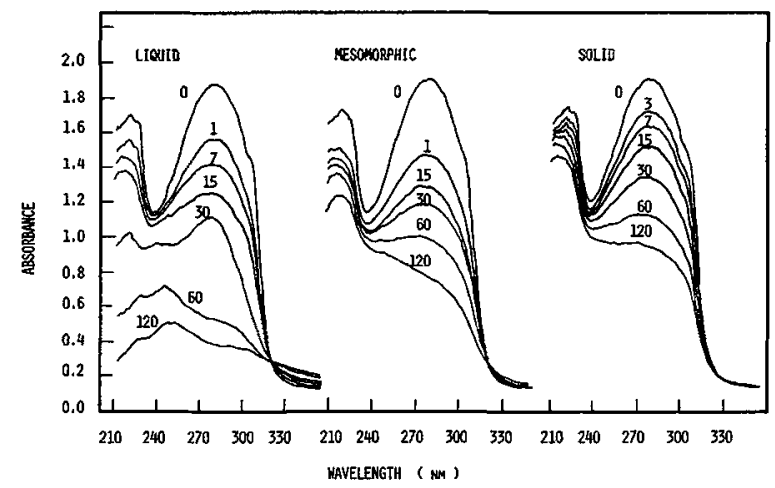

Fig. 1. - Change in ultraviolet absorption spectra on irradiation of cholesteryl trans-cinnamate in $\mathrm{KBr}$ pellets at the solid, mesomorphic and liquid states. The exciting light is wavelength longer than $300 \mathrm{~nm}$. The number shows the irradiation time in min.

in $\mathrm{KBr}$ pellets at a wavelength longer than $300 \mathrm{~nm}$ in the solid, mesomorphic and liquid states, the ultraviolet absorption spectra were changed gradually into those similar to that of photodimers of cinnamic acids and cinnamates. Under these conditions, characteristic infrared absorption bands at 980 and $1630 \mathrm{~cm}^{-1}$, which can be assigned to the out-ofplane hydrogen deformation made of trans-alkene and to the stretching modes of the carbon-carbon double bond of olefinic hydrocarbons, respectively, decreased gradually, and then reached a constant level about one-fourth of the initial value. These facts imply that cholesteryl trans-cinnamate in various states such as the solid, mesomorphic and liquid phases is converted into a dimer on irradiation at a wavelength longer than $300 \mathrm{~nm}$.
The monomer crystals were deposited on a quartz plate in the form of a thin layer by slow evaporation from a concentrated solution in benzene and then irradiated at a wavelength longer than $300 \mathrm{~nm}$ with a 500-W xenon lamp. On the irradiation, the ultraviolet absorption spectra of the thin layer were changed in similar manner to those of the $\mathrm{KBr}$ pellet at the solid phase. The reaction mixture in the thin layer had also similar infra-red absorption spectra to those in the $\mathrm{KBr}$ pellet.

To compare with this, the photoreaction in the isotropic solution was performed in hexane at $25^{\circ} \mathrm{C}$ using $2 \mathrm{wt}-\%$ of the cinnamate, and the characteristics of the reaction mixture were examined. In figure 2,

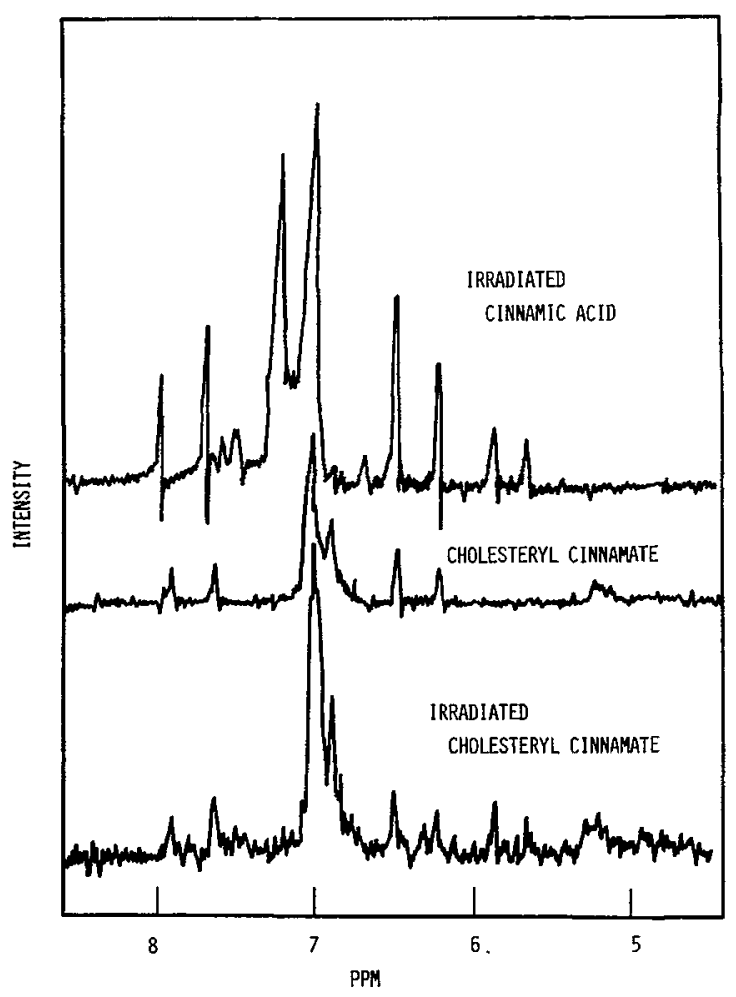

FiG. 2. - The NMR spectra of cholesteryl trans-cinnamate before and after irradiation in solution, and of cinnamic acid after irradiation in solution.

are shown the NMR spectra of cholesteryl transcinnamate and the reaction mixture with that of the mixture of trans- and cis-isomers of cinnamic acid. The spectrum of the mixture shows the peaks of protons attached to the trans- and cis-alkenes near 6.2-6.5 and 5.6-5.9 ppm, respectively. In the infra-red absorption spectrum, shown in figure 3 , the characteristic band at $980 \mathrm{~cm}^{-1}$ corresponding to the out-ofplane hydrogen deformation mode of trans-alkene decreased but the bands attributable to the stretching modes of the carbon-carbon double bond of olefinic hydrocarbons were observed at $1660-1640 \mathrm{~cm}^{-1}$. The product obtained on irradiation in solution should be the cis-isomer of the cinnamate, different from those obtained in the solid, mesomorphic and 


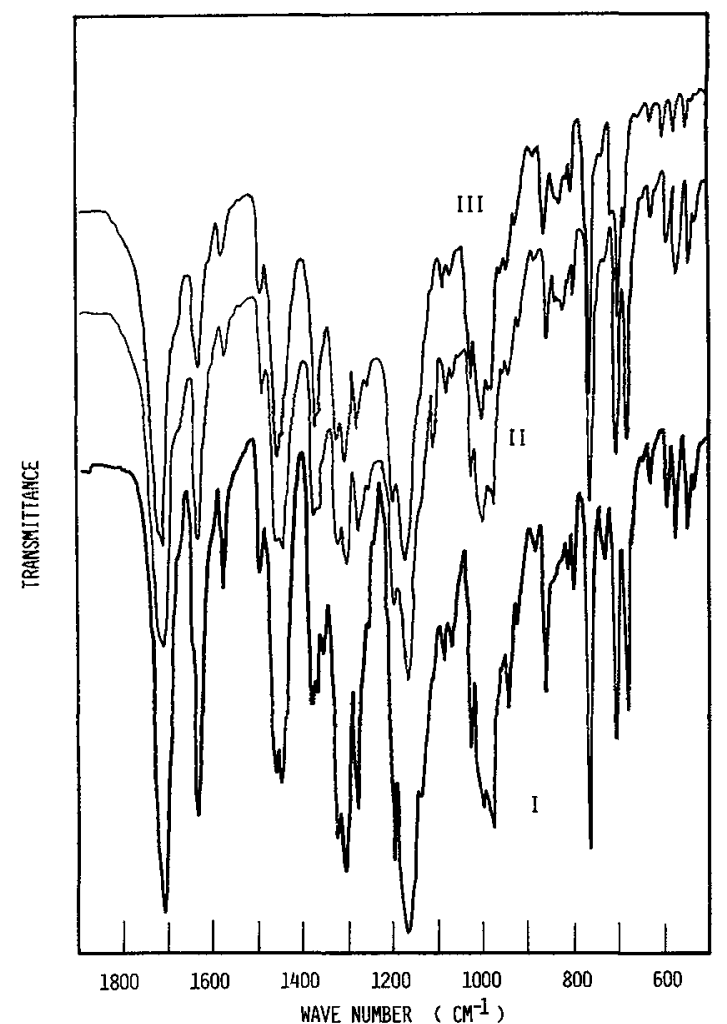

FIG. 3. - The infrared absorption spectra of cholesteryl transcinnamate (I) and its reaction mixtures after irradiation in solution (II) and in $\mathrm{KBr}$ matrix (III).

liquid states. This difference may be described partly by concentration effects of the compound.

The intensities of infrared absorption spectrum of the sample at 980 and $700 \mathrm{~cm}^{-1}$ were found to decrease and increase in proportion to the decrease of the olefinic double bond and to the increase of the cyclobutane-ring, respectively, in the reaction system [5]. Under the same condition, the intensity of ultraviolet absorption spectrum was found also to decrease as shown in figure 1 . The results of typical kinetics of photodimerization in $\mathrm{KBr}$ are plotted in figure 4, in which the relative intensity changes of $280 \mathrm{~nm}$ are plotted against the irradiation time. The intensity decreased gradually and then reached a constant level in all phases. The relative rate of photodimerization at the mesomorphic state was found to be higher than that at the isotropic liquid state. The photoreaction in the solid phase takes place at a much slower rate than in the other phases. This suggests that some kinds of ordering or arrangement besides the mobility of the molecules of cholesteryl transcinnamate enhance the rate and affects the course of the reaction in condensed states on irradiation.

When the reaction mixture containing the dimer was dissolved in diethyl ether and then irradiated with a light of $230 \mathrm{~nm}$, the ultraviolet absorption spectrum was changed partly into that of the original trans-cinnamate.

The quantum yields for the dimerization of the

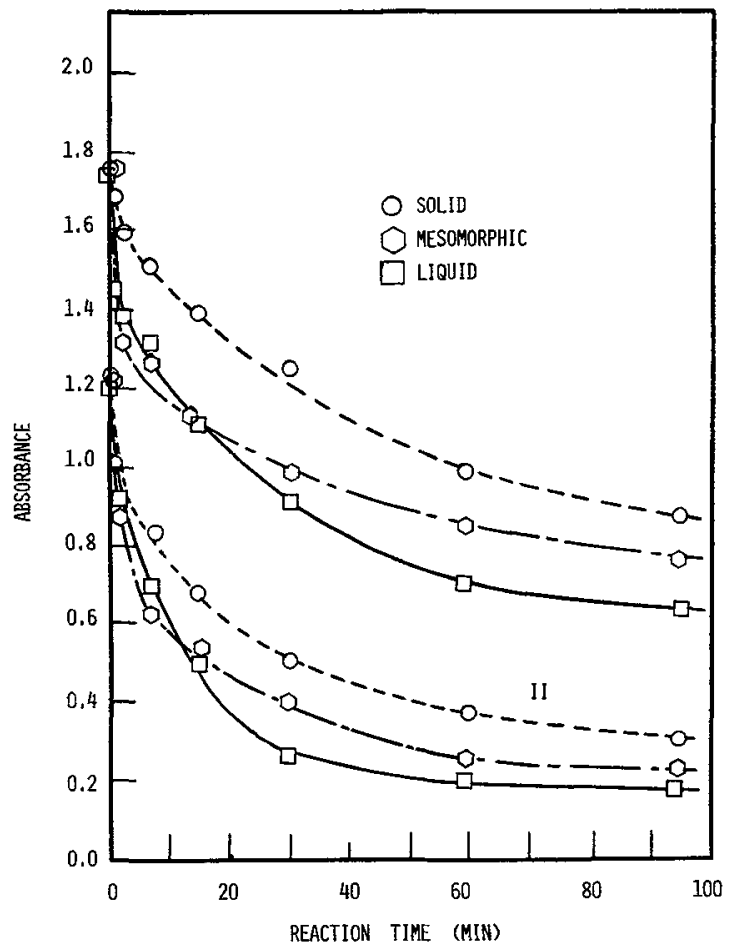

FIG. 4. - Kinetics of photoreaction of cholesteryl trans-cinnamate in $\mathrm{KBr}$ irradiated at a wavelength longer than $300 \mathrm{~nm}$ in the solid $\left(O\right.$, at $\left.25^{\circ} \mathrm{C}\right)$, mesomorphic $\left(O\right.$, at $\left.165^{\circ} \mathrm{C}\right)$ and liquid $\left(\square\right.$, at $\left.225^{\circ} \mathrm{C}\right)$. I : $1.45 \times 10^{-5} \mathrm{~mole} / \mathrm{g}, \mathrm{II}: 4.37 \times 10^{-6} \mathrm{~mole} / \mathrm{g}$.

cinnamate were measured. The quantum yield, $\varphi$, is defined by the equation :

$$
\varphi=-[\mathrm{d}(\text { double bonds }) / \mathrm{d} t] / I_{\text {abs }}
$$

where $-[\mathrm{d}($ double bonds $) / \mathrm{d} t]$ is the disappearing rate of the olefinic double bond per unit of volume, and $I_{\text {abs }}$ is the rate at which the incident light is absorbed per unit of volume of a pellet containing the sample. There are two infrared absorption bands, at 980 and $1630 \mathrm{~cm}^{-1}$, attributable to the olefinic double bond. The former was used for the measurement in this work.

An infrared absorption coefficient of the cinnamate was exactly determined from the calibration curve of the intensity $v s$ the monomer concentration in a pellet. $I_{\text {abs }}$ could not be precisely evaluated because of the ambiguity in the amount of scattered light, and should be equal to the intermediate value between two extreme ones calculated on the assumption that the scattered light is either all lost or not lost at all [6]. The extreme values are calculated as the difference between the intensity of the radiation transmitted through a pure $\mathrm{KBr}$ pellet $\left(I_{\mathbf{K B r}}\right)$ and a pellet containing the sample $\left(I_{\text {sam }}\right)$ in the former case, and between the incident light intensity $\left(I_{0}\right)$ and $I_{\mathrm{sam}}$ in the latter case. $I_{\mathrm{KBr}}$ was about $70-80 \%$ of $I_{0}$ at $280 \mathrm{~nm}$ under these conditions. The substitution of the upper limit of $I_{\text {abs }}, I_{0}-I_{\text {sam }}$, in the denominator of eq. (1) gives the quantum yield at the low limit, and vice versa. 
The initial quantum yields for the dimerization at morphic and isotropic liquid states, respectively, the lower limit are $0.2,0.3$ and 0.2 in the solid, meso- at $280 \mathrm{~nm}$.

\section{References}

[1] Lamola, A. A. and Turro, N. J., Energy Transfer and Organic Photochemistry (Interscience, New York) 1969, chap. 3.

[2] Ginsburg, D., G. M. J. Schmidt et al., Solid State Photochemistry (Verlag Chemie, Weinheim) 1976.

[3] Demus, D., Demus, H. and Zaschke, $\overline{\mathrm{H}} .$, Flussige Kristalle in Tabellen (VEB Deutsche Verlag, Leipzig) 1974, p. 288.

[4] Hatchard, C. G. and Parker, C. A., Proc. Roy Soc., Ser. A, 235 (1956) 518.
[5] Tanaka, Y., Sasaki, S., Kobayashi, A., Shiraki, M. and OKaDA, A., Paper presented at the 26th International Congress of Pure and Applied Chemistry, at 4-10 September, 1977, Tokyo.

[6] Fuchtbauer, W. and Matur, P., Photochem. Photobiol. 5 (1966) 323. 